\title{
Characteristic evaluation of soy-groundnut paneer
}

\author{
Smita Khodke ${ }^{1}$, Minakshi Pardhi ${ }^{2}$, Pramodini More ${ }^{3}$, Avinash Kakade ${ }^{4}$ \\ ${ }^{1}$ (Head, Department of Agril. Process Engg, College of Agril. Eng. \& Tech. VNMKV,Parbhani(MS) India \\ ${ }^{2}$ (Department of Agril. Process Engg, College of Agril. Eng. \& Tech. VNMKV,Parbhani(MS) India
}

\begin{abstract}
Soybean is an excellent source of protein and fat. However, beany flavour, indigestible components and anti-nutritional factors present in soybean pose obstacles in utilization of soybean. Soyapaneer one of the most nutritional products can be prepared from soymilk. Soypaneer contain 14 per cent proteins, $3.6 \%$ fats and about 72 per cent moisture content. Milk paneer, though it is popular, but it is expensive costing Rs.300/kg. Hence it is out of economy to reach the majority of Indian people. In this context soypaneer is an appropriate alternative to milk paneer. Cost of soypaneer is only one third of milk paneer (Rs.100/kg) and gives all nutritional advantages and psychological satisfaction of eating cow milk paneer dish. Groundnut milk is good source of protein. Fortification of soypaneer with groundnut milk may produce best quality of paneer with improved texture and taste. Soya-groundnut paneer is one of the most nutritional products, which can be prepared from different proportions of soymilk and groundnut milk. In the present investigation, soygroundnut paneer was prepared from different proportions of soymilk and groundnut milk. Further prepared soy-groundnut paneeer were evaluated for its proximate composition, textural characteristics and organoleptic properties. Soypaneer fortified with 10\% groundnut milk improved taste soy-groundnut paneer and reduced typical beany flavour of soypaneer. The soy-groundnut paneer prepared from 90:10 proportion of soymilk and groundnut milk produced maximum yield and best quality attributes in terms of proximate composition, textural characteristics and organoleptic properties as compared to other proportions of soymilk and groundnut milk.
\end{abstract}

Keywords: Soybean, Soypaneer, soymilk, Groundnut milk

\section{Introduction}

Soybean often called 'Golden miracle bean' is the world's foremost provider of protein and oil, used as health food, feed sources and industrial products. Madhya Pradesh produces about $75-80 \%$ of the total nation production of soybean. The other states, where grow significant amount of soybean are Maharashtra, Rajasthan and Uttar Pradesh. In India from total production of soybean, about 85 per cent used in oil processing, $10 \%$ is used for seeds and only $5 \%$ is used for processing of food products. There is lack of awareness about the processing and health benefits of soybean. Many misunderstanding and misconceptions about soybean and its

products also existed in the minds of consumers. Even the farmers who produce soybean did not know method of processing and mode for its consumption. Other important factors are non-availability of the products in Indian market suiting to Indian eating habits. This is mainly due to non-availability of appropriate technology suitable for Indian socio-economic conditions.

Soybean is an excellent source of protein and fat. However, beany flavour, indigestible components and anti-nutritional factors present in soybean pose obstacles in utilization of soybean. However, the antinutritional factors and indigestible components present soybean can be destroyed through the available processing technology like thermal processing.

Soypaneer one of the most nutritional product can be prepared from soymilk. It is a soft cheese-like food made by curdling soymilk with a coagulant (Raja et al., 2014) [1]. From one kg of cleaned and dry soybean about 6-8 liters of milk and after coagulation of milk about 1.5- $2 \mathrm{~kg}$ of soypaneer can be obtained. Soypaneer contains $15 \%$ protein, $3.6 \%$ fat and about $72 \%$ moisture content (Arora and Mittal, 1991)[2]. Although, milk paneer is popular among consumers, it is expensive and costing around $\square 300 \mathrm{~kg}^{-1}$. Hence, it is not possible to offer milk paner for the majority of Indian people. In this context, soypaneer can be an appropriate economical alternative to milk paneer costing around $\square 150 \mathrm{~kg}^{-1}$ and gives all nutritional benefits. Groundnut, an important cash crop is an annual legume. Its seeds are of rich source of edible oil (43-55 per cent) and protein (25-28 per cent). About two third of world population of groundnut is crushed for oil and the remaining one third is consumed as food.

Groundnut is particularly valued for its protein contents, which is of high biological value. Groundnut content more protein than meat, about two and half times more than eggs and far more than any other vegetable food except soybean and yeast. The protein groundnuts are well balanced, except for slight deficient in some of the essential amino acids. As it happens, these amino acids are abandoning milk, which can be combined with groundnut products for better results.

From $1 \mathrm{~kg}$ of groundnut about 8-liter milk can be obtained. Addition of groundnut milk to soymilk in paneer preparation will improve nutritional quality and taste of paneer. 
It is necessary to optimize the proportion of soy-groundnut milk for the production of paneer, which will have best quality attributes in terms of textural and organoleptic properties of soymilk and groundnut milk. Keeping above views, soy-groundnut paneer was prepared from different proportions of soymilk and groundnut milk. Further prepared soy-groundnut paneeer were evaluated for its proximate composition, textural characteristics and organoleptic properties and evaluated the best combination proportion of soy-groundnut milk for the preparation of paneer.

\section{Materials And Methods}

Variety of soybean JS-335 and variety of groundnut SB-11 were procured from seed processing plant, VNMKV, Parbhani. Selected variety of soybean was cleaned by removing under size wrinkled and damaged bean and soaked in tap water using bean to water ratio (1:3 W/V) For 8 to $10 \mathrm{hrs}$. at room temperature. The soaked water was decanted and the skins were removed by hand. The washed beans were grounded in mixture

Cum grinder for 3-5 minutes using bean to water ratio of 1:8. The slurry was heated for 20 minutes with continuous stirring, and then boiled slurry was filtered through double layer muslin cloth to get soymilk.

\section{Preparation of groundnut paneer}

Whole groundnut of selected variety were added in boiling water, then removed from heat and soaked in water for $7 \mathrm{~min}$. Then soaked groundnut skins were removed by hand. The cotyledons were soaked in $2 \%$ sodium bicarbonate overnight. The cotyledon rinsed with tap water, then blended with water $(1: 5 \mathrm{~W} / \mathrm{V})$, the blended slurry was heated for 15-20 minutes with continuous stirring. The slurry was filter through doublelayered muslin cloth to get groundnut milk.

\section{Preparation of soy-groundnut paneer}

The obtained soymilk and groundnut milk were mixed with different proportions as per experimental plan. The mixture was heated upto $70^{\circ} \mathrm{C}$, citric acid ( $2 \mathrm{gm} /$ liter of milk) was used as coagulant then stirring continuously, till the soluble solids and whey was separated visually. The obtained solid was filtered through the muslin cloth and pressed in paneer press for 15-20 minutes at constant pressure for each sample. The pressed solids was then removed from the press box and immediately transferred in chilled water and stored in refrigerator. The soymilk and groundnut milk is mixed with proportion given below.

\begin{tabular}{|c|c|c|}
\hline Sr. No & Soymilk $\%$ & Groundnut milk \% \\
\hline 1 & 100 & 0 \\
\hline 2 & 90 & 10 \\
\hline 3 & 80 & 20 \\
\hline 4 & 70 & 30 \\
\hline 5 & 60 & 40 \\
\hline 6 & 50 & 50 \\
\hline 7 & 0 & 100 \\
\hline
\end{tabular}

Total 7 samples were prepared in the laboratory. Then the prepared samples were heated upto $70^{\circ} \mathrm{C}$ and coagulated with $2 \%$ citric acid solution with continuous stirring till the clear whey separated, then the content was allowed to cooled at room temperature. The obtained whey was removed by filtration through doublelayered muslin cloth, and then obtained solid was finally traced in a developed paneer press under constant pressure for 15 minutes. The paneer block so obtained was placed in chilled water then stored in refrigeration condition.

\section{Proximate composition of Soy-groundnut paneer}

Proximate composition of soy-groundnut paneer samples of different proportions, like moisture content (Air oven method), fat (Soxhlet method), ash , protein ( $\mathrm{N} x 6.25$ ) and carbohydrates were determined. The yield of soy groundnut paneer samples were measured using standard procedures.

\section{Textural properties of Soy-groundnut paneer}

The textural properties of soy-groundnut paneer prepared from different proportions of soymilk and groundnut milk were evaluated using Textural Analyzer (TAX -II-TI), as per method suggested by Bourne (1968) [3]. Paneer samples of $10 \mathrm{~mm}$ thickness were compressed successfully using a $25 \mathrm{~mm}$ dia perplex cylindrical probe. The sample was compressed up to 30 per cent of their original length. The speed of the probe was fixed at $0.5 \mathrm{~mm} / \mathrm{s}$ during the pre-test, compression and relaxation of the samples. During testing samples were held manually against the base plate. 


\section{Sensory evaluation of Soy-groundnut paneer}

For sensory evaluation, the soy-groundnut paneer samples were cut into pieces of uniform size of $10 \mathrm{x}$ $10 \mathrm{~mm}$. A panel consisting of ten semi-trained members from staff of College of Agricultural Engineering and Technology, VNMKV, Parbhani was formed after screening on the basis of their interest, motivation and willingness to taste the samples. The panelists were suitably trained for the evaluation of soy-groundnut paneer. Sensory evaluation was carried out by the standard method (Anonymous, 1971)[4]. The 9-point hedonic scale was used for evaluation by assigning numerical values for different quality attributes of soy-groundnut paneer viz. colour, flavour, test, texture appearance and overall acceptability. The data was tabulated and evaluated statistically.

\section{Yield of soy-groundnut paneer}

\section{Result And Discussion}

From Table 1, it is observed as the yield of the soy-groundnut paneer varies with different proportion. The maximum yield was obtained in the $100: 0$ and $90: 10$ proportions $17.1 \%$ and $15.6 \%$ respectively, whereas the minimum yield was obtained from the proportion 50:50. This may be due to more fat content in the groundnut milk. The yield of the soy-groundnut paneer decreased with increasing groundnut milk percentage. Table 1 revealed that the 50:50 proportion soy-groundnut paneer produced very low yield of soy-groundnut paneer. It was observed during experimentation that the groundnut milk increases, coagulation of milk was not properly and whey was separated from the solids. This may be the reason for the reduction of yield as percentage of groundnut milk increase also it was observed that prepared soy-groundnut paneer from 50:50 proportion was not good ( Harjai and Singh,2007)[5].

\section{Proximate analysis of soy-groundnut paneer}

The moisture content of soy-groundnut paneer prepared from different proportions of soymilk and groundnut milk ranged between 68 to 73.8 per cent (Table 1). The maximum moisture content $(73.85 \%)$ was observed in the proportion of 50:50, whereas the minimum moisture content $(68 \%)$ was observed in the proportion of 90:10. The soy-groundnut paneer prepared from 90:10 proportions was having desired hardness as compared to other samples prepared from different proportions of soymilk and groundnut.

Table 1 Yield and Proximate analysis of soy-groundnut paneer with different proportion of soymilk and groundnut milk.

\begin{tabular}{|c|c|c|c|c|c|c|}
\hline $\begin{array}{c}\text { Proportion } \\
\text { (Soymilk: } \\
\text { Groundnut- milk) }\end{array}$ & $\begin{array}{l}\text { Yield } \\
(\%)\end{array}$ & $\begin{array}{c}\text { Moisture } \\
(\%)\end{array}$ & $\begin{array}{l}\text { Fat } \\
(\%)\end{array}$ & $\begin{array}{l}\text { Ash } \\
(\%)\end{array}$ & $\begin{array}{c}\text { Protein } \\
(\%)\end{array}$ & $\begin{array}{c}\text { Carbohydrates } \\
(\%)\end{array}$ \\
\hline 100:0 & 17.1 & 71.40 & 3.52 & 1.33 & 15.79 & 7.62 \\
\hline $90: 10$ & 15.6 & 68.00 & 3.5 & 1.24 & 15.5 & 11.76 \\
\hline $80: 20$ & 14.7 & 69.75 & 3.65 & 1.25 & 14.4 & 10.9 \\
\hline $70: 30$ & 12.6 & 71.50 & 3.74 & 1.29 & 13.7 & 9.75 \\
\hline $60: 40$ & 10.0 & 72.45 & 4.6 & 1.31 & 12.9 & 8.68 \\
\hline $50: 50$ & 8.8 & 73.80 & 4.8 & 1.32 & 12.3 & 7.69 \\
\hline $\mathrm{SE} \pm$ & - & 0.588 & 0.07 & 0.013 & 0.123 & 0.023 \\
\hline $\mathrm{CD}$ & - & $* * 1.81$ & $* * 0.20$ & $* * 0.042$ & $* * 0.37$ & $* * 0.07$ \\
\hline
\end{tabular}

** Significant at 5\% level of significance

The fat content of soy-groundnut paneer prepared from different proportion of soymilk and groundnut milk was ranged between 3.5 to 4.8 per cent. The maximum fat content $(4.8 \%)$ was observed in the proportion of 50:50. A lowest value of fat content 3.5 per cent was observed in the proportion of 90:10.

The range of ash content in soy-groundnut paneer prepared from different proportions of soymilk and groundnut milk was 1.24 to $1.33 \%$. The maximum ash content 1.33 and 1.32 per cent was recorded in the proportion 100:0 and 50:50 respectively, whereas in minimum ash content $(1.24 \%)$ was observed in the proportion 90:10. From Table 1, it is observed that the moisture content, fat and ash content increased with increasing the groundnut milk percentage.

The protein content of soy-groundnut paneer ranged between 12 to 15.79 per cent. The lowest protein content was observed in the proportion of 50:50, whereas the proportion of 100:0 and 90:10 were significantly superior as regards to the protein content in other proportion. 
The carbohydrate content in soy-groundnut paneer was in the range of 7.62 to 11.76 per cent. The maximum carbohydrates were observed in the proportion of 90:10, whereas the lowest carbohydrates $(7.62 \%)$ were observed in the proportion of 50:50. The protein content and carbohydrates percent was decreased in the soy-groundnut paneer with decreasing soymilk percentage.

\section{Textural analysis of soy-groundnut paneer}

Table 2 indicates that all textural properties hardness, chewiness, cohesiveness, gumminess, and springiness of soy-groundnut paneer prepared from different proportions of soymilk and groundnut milk significantly varies. Mathare et al. (2009) [6] also studied different textural properties of soypaneer like hardness, springiness, chewiness, cohesiveness and reported similar trend.

Table 2 Textural properties of soy-groundnut paneer with different proportion of soymilk and groundnut milk.

\begin{tabular}{|c|c|c|c|c|c|}
\hline \multirow{2}{*}{$\begin{array}{c}\text { Proportion } \\
\text { (Soymilk: } \\
\text { Groundnut } \\
\text { milk) }\end{array}$} & \multicolumn{5}{|c|}{ T.P.A. characteristics } \\
\hline & $\begin{array}{c}\text { Hardness } \\
\text { (g) }\end{array}$ & $\begin{array}{c}\text { Chewiness } \\
(\mathrm{g})\end{array}$ & Cohesive-ness & Springi-ness & Gummi-ness (g) \\
\hline $100: 0$ & 666.7 & 305.2 & 0.60 & 1.14 & 380.24 \\
\hline $90: 10$ & 659.1 & 309.64 & 0.54 & 0.87 & 355.91 \\
\hline $80: 20$ & 512.6 & 223.79 & 0.49 & 0.89 & 251.17 \\
\hline $70: 30$ & 435.7 & 108.44 & 0.34 & 0.87 & 148.14 \\
\hline $60: 40$ & 211.6 & 61.11 & 0.33 & 0.73 & 70.25 \\
\hline $50: 50$ & 93.2 & 14.30 & 0.26 & 0.59 & 24.44 \\
\hline $\mathrm{SE} \pm$ & 0.75 & 0.47 & 0.0068 & 0.05 & 13.65 \\
\hline $\mathrm{CD}$ & $* * 2.32$ & $* * 1.44$ & $* * 0.02$ & $* * 0.015$ & $* * 41.9$ \\
\hline
\end{tabular}

** Significant at 5\% level of significance

The hardness of the sample prepared from 90:10 and 80:20 proportion of soymilk and groundnut milk was similar to hardness of paneer sample prepared from $100 \%$ soymilk. As the groundnut milk percentage increases in the paneer sample hardness value decreased. This may be due to increase in fat content. Similar results were also reported by Uprit and Mishra (2004)[7] who studied the textural kinetics of soy fortified paneer during salt treatment process.

As the groundnut milk percentage increased the values of textural properties decreased. All the textural properties soy-groundnut paneer prepared from different proportions were highly significant at $5 \%$ level of significance. The soy-groundnut paneer prepared from proportions 90:10 and 80:20 were superior with respect to all textural properties.

\section{Sensory Evaluation of Soy-groundnut paneer}

Soy-groundnut paneer prepared from the proportions 70:30, 60:40: 50:50 were found a fragile and brittle texture and obtained less score for all the sensory attributes. It was observed during experimentation that as groundnut milk percentage increased rancid flavour increased. This may be due to more fatty acids present in the groundnut.

From Table 3, it is observed that score of all sensory properties of soy-groundnut paneer were decreased with increasing groundnut milk percentage. Statistically all sensory properties were highly significant at 5 per cent level of significance. It was observed that the body and texture and overall acceptability of the proportions 90:10, 80:20 were equivalent to 100 per cent soymilk paneer.

Table 3 Sensory score of soy-groundnut paneer with different proportions of soymilk and groundnut milk.

\begin{tabular}{|c|c|c|c|c|c|c|}
\hline \multirow{2}{*}{$\begin{array}{c}\text { Proportion } \\
\text { (Soymilk: } \\
\text { Groundnut milk) }\end{array}$} & \multicolumn{7}{|c|}{ Sensory attributes } \\
\cline { 2 - 7 } & Colour & Flavour & Appearance & Taste & $\begin{array}{c}\text { Body and } \\
\text { texture }\end{array}$ & $\begin{array}{c}\text { Overall } \\
\text { acceptability }\end{array}$ \\
\hline $100: 0$ & 7 & 6.3 & 7 & 7.5 & 7.4 & 7.5 \\
\hline $90: 10$ & 7.4 & 7.8 & 8.6 & 7.5 & 8 & 8 \\
\hline $80: 20$ & 7.33 & 6.2 & 7.33 & 7 & 7.33 & 6.3 \\
\hline $70: 30$ & 5 & 4 & 4 & 4.3 & 3 & 3 \\
\hline $60: 40$ & 3 & 2 & 2 & 2 & 1 & 1 \\
\hline $50: 50$ & 2 & 1 & 1 & 1 & 1 & 1 \\
\hline SE \pm & 0.21 & 0.20 & 0.20 & 0.19 & 0.21 & 0.17 \\
\hline CD & $* * 0.60$ & $* * 0.56$ & $* * 0.57$ & $* * 0.45$ & $* * 0.58$ & $* * 0.47$ \\
\hline
\end{tabular}

** Significant at $5 \%$ level of significance 


\section{Conclusion}

The soy-groundnut paneer contains 15 per cent protein, 3.5 per cent fats and about 68 per cent moisture content. Soypaneer fortified with $10 \%$ groundnut mil improved taste soy-groundnut paneer and reduced typical beany flavour of soypaneer. The soy-groundnut paneer prepared from 90:10 proportion of soymilk and groundnut milk produced maximum yield and best quality attributes in terms of proximate composition, textural characteristics and organoleptic properties as compared to other proportions of soymilk and groundnut milk.

\section{References}

[1] Raja, J, H.A. Punoo, F.A Masoodi,. Comparative study of soypaneer prepared from soymilk, blends of soymilk and skimmed milk. J. Food Process Techno. 15 (2), 2014,301-305.

[2] Arora, S. and B.K. Mittal,Preparation and evaluation of soy paneer. J.Food Sci. Technol. 28(1) 1991, 15-17.

[3] Bourne, M.C., Texture profile of ripening pears. J. of Food Sci. Technol, 33,1968, 223-226.

[4] Anonymous, Guide for Sensory Evaluation of Foods, Part-I, Optimum requirements (IS-6273). 1971, Bureau of Indian Standards, Manak Bhavan, New Delhi.

[5] Harjai, N. and G. Singh, Effect of soybean varieties on physico-chemical, textural and sensory properties of soypaneer. J. Food Sci. Technol. 46(4, 2007, 331-334

[6] Mathare, S.S., S. B. Bakal, T.M.R. Dissanayake and S.K. Jain, Effect of coagulation temperature on texture and yield of tofu. J. Nat. Sci. Foundation Sri Lanka. 27 (4), 2009,263-267.

[7] Uprit, S. and H. N. Mishra, Instrumental textural profile analysis of soy fortified pressed chilled acid coagulated curd (Paneer). Int. J. Food Properties. 7 (3), 2004, 367-378. 